\title{
GOLD B COPD patients: are they all the same?
}

\author{
(D) José Coutinho Costa \\ (iD) Jõo Neiva Machado' \\ DLídia Marília Valente Marques Sousa Gomes ${ }^{1}$ \\ (iD) Cidália Maria Regino Rodrigues ${ }^{1}$
}

1. Pneumology Unit, University Hospital Center of Coimbra, Hospital Geral, Coimbra, Portugal.

http://dx.doi.org/10.1590/1806-9282.66.5.569

Dear Editor,

COPD is a disease characterized by progressive and persistent airflow limitation. The objectives of COPD assessment are to determine the level of airflow limitation, its impact on the health status of the patient, and the risk of future events (such as exacerbations, hospital admissions, or death). In order to achieve these objectives, the assessment should consider the severity of the airflow limitation, the magnitude of the patient's symptoms, the history of exacerbations, and the presence of comorbidities'.

The natural history of GOLD B COPD patients is not well described or understood ${ }^{2}$. GOLD B patients are defined by low rates of exacerbation ( $<2$ exacerbations per year without hospitalization) and high symptom burden. These patients may have more exacerbations in the future and, consequently, change their GOLD category. In the ECLIPSE study ${ }^{2}$, only $36 \%$ of patients in group B remained stable after 1 year, 7\% and 35\% deteriorated into higher-risk categories, i.e., $\mathrm{C}$ and $\mathrm{D}$, respectively, and $22 \%$ improved to group A.

GOLD B COPD patients, although very symptomatic, are considered low risk. Studies have also shown that these patients have a high morbidity and mortality rate, which may influence future follow-up and therapy options. Moreover, there appears to be some heterogeneity in group B, in which a subgroup of patients progresses over time to higher risk categories.
The objective of our study is to evaluate the functional and clinical characteristics of COPD patients belonging to group $\mathrm{B}$ and explain the driving factors for their tendency to shift to group D over time.

Our study is a prospective analysis of a convenience sample of COPD patients attending a pulmonology appointment at the Pneumology Unit, University Hospital Center of Coimbra. Demographic, functional, and clinical data of all the patients from 2017 were analyzed, and a second evaluation took place 12 months later. Patients with other chronic respiratory diseases, such as Asthma/COPD Overlap, interstitial disease, cystic fibrosis, or lung cancer, were excluded.

The statistical analysis was completed using the IBM SPSS ${ }^{\circledR}$ statistical program, version 20 . The categorical variables were described with percentages and the quantitative variables with mean and standard deviation. All associations were established using the Chi-Square Test or Fisher Exact Test for categorical variables and the T-Test for independents samples or the Mann Whitney Test for continuous variables. All the tests were considered significant when the p-value did not exceed 0.05 .

We included 53 patients, 85\% male, aged 55 to 94 years. In 2017, our sample consisted of 25\% (13) GOLD A patients, 54\% (29) GOLD B, 8\% (4) GOLD C, and 13\% (7) GOLD D. In the comparative analysis between 
group A and B, we found that the FEV1 \% predicted was similar between the two groups [50,8\% $(1385 \mathrm{ml})$ vs $45,3 \%(1250 \mathrm{ml}), \mathrm{p}=0.138$ ], and a significant proportion of patients in group B had emphysema $(79.3 \% \mathrm{vs}$ $38.5 \%, p=0.015)$, chronic bronchitis $(68.9 \%$ vs $30.7 \%$, $\mathrm{p}=0.041)$, and cardiovascular comorbidities $(89.6 \%$ vs $53.8 \%, p=0.016)$. The cardiovascular comorbidities considered were heart failure, atrial fibrillation, ischemic heart disease, diabetes mellitus, and high blood pressure.

After 12 months of follow-up, of the 29 GOLD B patients, the majority (18) was stable and remained in group B; 10 patients progressed to GOLD D; and 1 patient was reclassified to GOLD A. Considering the baseline characteristics in 2017, patients who progressed to GOLD D had a FEV1 \% predicted significantly lower than patients who remained in group B [mean 48.6\% (1320ml) vs 36.9\% (790ml), $\mathrm{p}=0.014$ ]. There were no statistically significant differences regarding age, gender, body mass index, smoking status, chronic bronchitis, emphysema, cardiovascular comorbidities, degree of dyspnea, and FVC (Table 1). There were no changes in inhaled treatment during the follow-up period.

TABLE 1. BASELINE CHARACTERISTICS OF PATIENTS FROM 2017 WHO REMAINED GOLD B AND PATIENTS PROGRESSED TO GOLD D AT 12 MONTHS OF FOLLOWUP

\begin{tabular}{|c|c|c|c|}
\hline \multirow{2}{*}{ Variables } & \multicolumn{2}{|c|}{ GOLD } & \multirow{2}{*}{$\mathrm{p}$-value } \\
\hline & $B(n=18)$ & $D(n=10)$ & \\
\hline Age - years (Mean \pm SD) & $74.7 \pm 8.9$ & $72.5 \pm 8.1$ & $p=0.591$ \\
\hline $\mathrm{BMI}-(\mathrm{Kg} / \mathrm{m} 2)($ Mean $\pm \mathrm{SD})$ & $28.5 \pm 4.1$ & $27.2 \pm 4.9$ & $p=0.573$ \\
\hline Pack years (Mean \pm SD) & $50.4 \pm 22.8$ & $43.8 \pm 17.7$ & $p=0.629$ \\
\hline Chronic bronchitis (\%) & $50 \%(9)$ & $80 \%(8)$ & $p=0.099$ \\
\hline Emphysema (\%) & $88.9 \%(16)$ & $100 \%(10)$ & $p=0.5$ \\
\hline Cardiovascular comorbidity (\%) & $72.2 \%(13)$ & $90 \%(9)$ & $p=0.118$ \\
\hline Dyspnoea - mMRC (median) & 2 & 2 & $p=0.121$ \\
\hline FVC\% (Mean \pm SD) & $66.9 \% \pm 9.9$ & $66.8 \% \pm 12.3$ & $p=0.980$ \\
\hline FEV1\% (Mean \pm SD) & $48.6 \% \pm 14.3$ & $36.9 \% \pm 11.3$ & $p=0.014$ \\
\hline
\end{tabular}

Several studies have investigated predictive factors for exacerbation and mortality in COPD. Although FEV1 by itself is not sufficiently accurate as a predictor of exacerbation, we know that there is a significant relationship between airflow limitation and the risk of exacerbation and death'. The risk factors for a greater decline in FEV1 are current smoking, emphysema, and exacerbations ${ }^{3}$. Recently, Lange et al. ${ }^{4}$ reported that the rate of decline in FEV1 in patients with COPD with low FEV1 in early adulthood (indicating suboptimal lung growth) is lower in comparison with COPD patients with normal FEV1 in early adulthood $(27 \mathrm{ml}$ versus $52 \mathrm{ml} /$ year, respectively). These findings suggest that the variation in lung function decline in COPD is influenced by multiple factors. We also know that COPD is associated with multiple comorbidities that may have a significant impact on prognosis ${ }^{1}$. Comorbidities are not associated with the degree of obstruction and have a cumulative effect on mortality ${ }^{2}$.

Overall, in our study, GOLD B patients had more cardiovascular comorbidities, emphysema, and chronic bronchitis than GOLD A patients, which may contribute to their high symptom burden. In addition, GOLD B patients who progressed to GOLD D had significantly lower FEV1, indicating that deterioration in airflow limitation is associated with an increased prevalence of exacerbations and disease progression. We think that these data should be taken preciously as the re-classification of patients based on an event (i.e. exacerbation) might be dangerous. However, this study has limitations that must be mentioned. The fact that our sample consisted of a convenience sample of only 53 patients may have conditioned our results.

\section{REFERENCES}

1. Global Initiative for Chronic Obstructive Lung Disease - GOLD. Global Strategy for the Diagnosis, Management, and Prevention of Chronic Obstructive Pulmonary Disease. 2018 Report. [cited 2019 Sept 05]. Available from: https://goldcopd.org/wp-content/uploads/2017/11/GOLD-2018v6.0-FINAL-revised-20-Nov_WMS.pdf

2. Agusti A, Edwards LD, Celli B, Macnee W, Calverley PM, Müllerova H, et al; ECLIPSE Investigators. Characteristics, stability and outcomes of the 2011 GOLD COPD groups in the ECLIPSE cohort. Eur Respir ). 2013;42(3):636-46.

3. Vestbo |, Edwards LD, Scanlon PD, Yates |C, Agusti A, Bakke P, et al; ECLIPSE Investigators. Changes in forced expiratory volume in 1 second over time in COPD. N Engl | Med. 2011;365(13):1184-92.

4. Lange P, Marott JL, Vestbo J, Olsen KR, Ingebrigtsen TS, Dahl M, et al. Prediction of the clinical course of chronic obstructive pulmonary disease, using the new GOLD classification: a study of the general population. Am J Respir Crit Care Med. 2012;186(10):975-81. 